\title{
Method for installing cryogenic fuel tanks on the deck of BelAZ 7513 mining dump truck
}

\author{
Georgiy Dubov ${ }^{1 *}$, Dmitriy Trukhmanov ${ }^{1}$, Sergey Nokhrin $^{2}$, and Aleksey Sergel ${ }^{3}$ \\ ${ }^{1}$ T.F. Gorbachev Kuzbass State Technical University, Department of Mechanical Engineering Tech- \\ nology, 28 Vesennya st., Kemerovo, the Russian Federation \\ ${ }^{2} \mathrm{OOO}$ «Sibir-Energo», 13 Schyorsa st., Novokuznetsk, the Russian Federation \\ ${ }^{3} \mathrm{OAO}$ «BELAZ» - Management Company of Holding «BELAZ-HOLDING», 440 let Octyabrya st., \\ Zhodino, Minsk region, Republic of Belarus
}

\begin{abstract}
The state of the issue of the relevance and efficiency of the technology of using liquefied natural gas as a partial replacement of diesel fuel in mining vehicles is considered. It is argued that this technology does not require complex and time-consuming re-engineering of internal combustion engines, which makes it economically feasible. It is noted that liquefied natural gas seems to be the most promising alternative to petroleum motor fuels in heavy-duty mining dump trucks. The use of liquefied natural gas as a motor fuel reduces the environmental burden; increases the energy efficiency of the rock mass hauling process and reduces fuel costs. It is said that developments aimed at substantiating and choosing design and layout solutions for the placement and arrangement of cryogenic equipment on mining vehicles are relevant. The new method for installing cryogenic fuel tanks on the deck of the BelAZ 7513 series mining dump truck with a payload capacity of 130 tons is described in detail. Layout solutions for the modernization of the deck of the BelAZ 7513 series dump truck allowing placing additional cryogenic equipment on its board are presented. The data presented indicate that the successful implementation of the proposed method is confirmed by the project on equipping the BelAZ 75131 mining dump truck with cryogenic onboard fuel systems, implemented in practice.
\end{abstract}

\section{Introduction}

The global consumption of mineral resources is increasing annually, which poses urgent tasks for the scientific community and business to increase the environmental and economic efficiency of their production. The efficiency of open-cast mining of mineral resources directly depends on the type of vehicles used. Today, the main type of vehicles for rock mass haulage is heavy-duty mining dump trucks [1-4].

At present, natural gas, which can be used as motor fuel without any advanced processing after its production, transportation and liquefaction, is recognized as an economically viable alternative fuel for motor vehicles [5-6].

\footnotetext{
*Corresponding author: nikokem@mail.ru
} 
The use of liquefied natural gas as a motor fuel for mining vehicles today has great prospects. Liquefied natural gas is a fuel that is significantly cheaper than diesel. The technology of using liquefied natural gas as a partial replacement of diesel fuel does not require complex and time-consuming re-engineering of internal combustion engines, which makes this technology economically feasible for use in mining trucks; reduces the environmental burden; increases the energy performance of the rock mass hauling process [7-9].

Today, in many countries, work is underway to convert off-road equipment - tractors, tugs, drilling rigs, heavy-duty vehicles and mining trucks - to liquefied natural gas. One example is a project implemented by Caterpillar (USA). In Mexico since 2016 and in Turkey since 2018, the first Caterpillar mining dump trucks with a payload capacity of 130 and 220 tons equipped with cryogenic onboard fuel systems [10-16] are operating in test mode in gold mines.

Currently, the developed methods for assessing the technical and economic indicators of cryogenic onboard fuel systems allow qualitatively and quantitatively: to determine the replacement coefficient of diesel fuel with liquefied natural gas $\left(\mathrm{K}_{\mathrm{s}}\right)$ during gas/diesel dualfuel operation of mining dump trucks; to evaluate the economic efficiency of mining dump trucks equipped with cryogenic onboard fuel systems; determine the actual life of cryogenic onboard fuel systems and their mean time between failures [17].

Implementation of projects for the production and consumption of liquefied natural gas in Russia is at the initial stage of its development. The weak presence in Russia of its own large-capacity technologies for liquefying natural gas, regulatory, technical and operational documentation for cryogenic on-board fuel equipment makes Russian projects dependent on foreign suppliers of technology, equipment and services. The technical requirements for cryogenic onboard fuel systems of BelAZ mining dump trucks, developed relatively recently, as well as specialized technological equipment will give a further impetus to the development and implementation of domestic projects for the production and consumption of liquefied natural gas in relation to mining vehicles [18-19].

In this regard, developments aimed at substantiating and choosing constructive and layout solutions for the placement and arrangement of cryogenic equipment mining vehicles in conjunction with mining, ergonomic and environmental requirements, as well as the subsequent study of their operational characteristics, are relevant.

The aim of this work is to develop a method for installing cryogenic fuel tanks on the deck of the BelAZ 7513 series mining dump truck.

\section{Results and Discussion}

The development relates to the field of mining engineering, in particular, to the BelAZ 7513 series mining dump trucks equipped with a deck sufficient to place cryogenic fuel tanks on it.

A method (http://autotogas.ru/) of installing gas equipment on motor vehicles for various purposes implemented by Chelavtotrans LLC (Chelyabinsk, Russia) is known. In this installation method, high-pressure gas cylinders are installed directly on the underbody of the vehicle.

The disadvantages of this technical solution are:

- the impossibility of using more technologically advanced and lighter cryogenic tanks (tanks) due to their large dimensions and limited space under the body;

- lack of direct visual control of fuel tanks, which reduces safety during operation;

- difficulty in the process of lifting a loaded body due to an increase in its mass and dis-

placement of the center of gravity;

- the complexity of installation, maintenance and refueling of gas equipment;

- the need for additional measures to reinforce the vehicle body and frame. 
It is known that Kovdor Mining and Processing Plant LLC (Kovdor, Russia) has been implementing a project for the conversion of mining dump trucks to gas/diesel dual-fuel operation since 2015 (https://b-ort.com/analytics/item/170669. html).

In this installation method, the cryogenic fuel tank was located on the right side of the mining dump truck frame under the body between the front and rear axles. Due to the increase in the space for placing fuel tanks, it became possible to use more technologically advanced cryogenic fuel tanks instead of high-pressure cylinders when operating the gas/diesel dual-fuel vehicle and, as a result, simplifying the design and reducing the number of valves.

The disadvantages of this method were the following:

- complexity or inability to strengthen the load-bearing metal structures of a mining truck at the site of a cryogenic fuel tank placement, which increases the likelihood of emergency downtime;

- lack of direct visual control of cryogenic fuel tank, which reduces safety during its operation;

- significant limits of the volume of cryogenic fuel tanks used due to their location, which increases the number of fueling cycles per shift, which leads to a decrease in the performance of the rock mass hauling process;

- lack of additional protection for cryogenic fuel tanks during loading and hauling;

- complexity of installation, maintenance and refueling of cryogenic fuel tanks.

There is a method of installing cryogenic fuel tanks on the deck of the BelAZ 75485 mining dump truck, proposed by V. Gerasimov in the article "Conversion of mining dump trucks to gas/diesel and gas operation using onboard liquefied natural gas fuel systems", "NM equipment" No. $\quad$ 1, 2005 (Russia) (http://www.rmo.ru/ru/nmoborudovanie/nmoborudovanie/2005-1/29_33_nmo_1_05.pdf).

This method consists of installing one 560 liter cryogenic fuel tank on the deck of a mining truck to the right of the cab as viewed in the direction of vehicle motion.

The disadvantages of this method were the following:

- lack of open access to information about the installation process does not make it possible to assess the complexity and practical feasibility of the known method, as well as maintaining the dump truck performance after installing cryogenic tanks;

- judging by the available publications, the known method is intended only for use on the BelAZ 75485 model with a loading capacity of up to 42 tons and involves the installation of only one tank with a capacity of not more than $560 \mathrm{l}$, which makes it irrational to use this method for BelAZ models with a higher loading capacity, and therefore, significantly limits the performance of the rock mass hauling process;

- lack of additional protection makes cryogenic tanks vulnerable to the effects of the external environment and the hauled rock mass, which reduces the safety during operation of the truck with installed cryogenic tanks.

The main objectives of the new developed method for installing cryogenic fuel tanks on the deck of the BelAZ 7513 series dump trucks are:

- efficient and easy-to-maintain placement of cryogenic fuel tanks on the deck of the BelAZ 7513 series dump truck for its gas/diesel dual-fuel operation;

- increase of working capacity, safety, reliability and convenience during gas/diesel dualfuel operation of the BelAZ 7513 series dump truck.

The technical result of the proposed technical solution: simplification of the installation process and minimization of preparatory measures, as well as increasing the performance of the rock mass hauling process and safety during gas/diesel dual-fuel operation of a mining truck.

The claimed technical solution is illustrated by drawings, where the general layout of equipment on the deck of the BelAZ 7513 dump truck is shown in Fig. 1; the diagram of 
the BelAZ 7513 dump truck deck reinforcement is presented in Fig. 2; the option of installing a gate on the front handrail of the dump truck deck and the site on the deck for the placement of air-start system cylinders is shown in Fig. 3; the option of installing a gate on the left handrail of the dump truck deck and the site on the deck for the placement of airstart system cylinders is presented in Fig. 4; the diagram of the installation of the modernized ladder on the BelAZ 7513 series dump truck is shown in Fig. 5; in Fig. 6 there is the diagram for the installation of the protective canopy above the frame with cryogenic fuel tanks fixed in it.

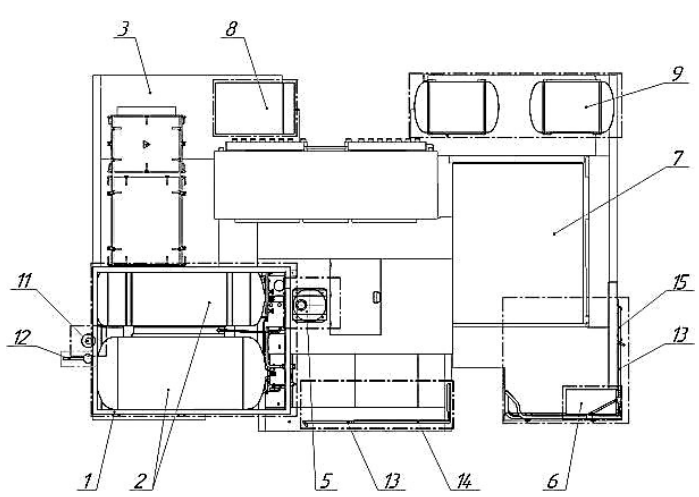

Fig. 1. The general layout of equipment on the deck of a BelAZ 7513 dump truck.

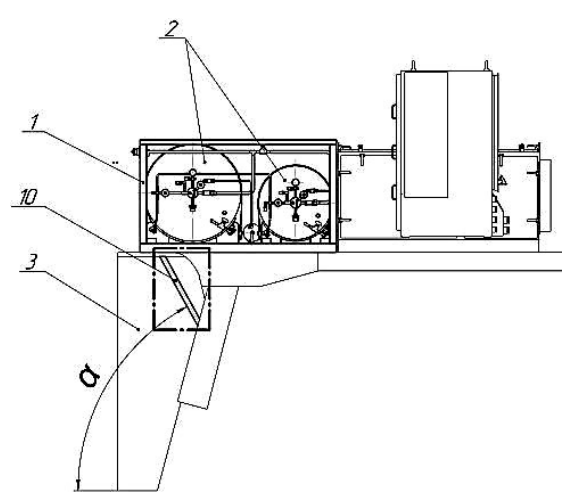

Fig. 2. The diagram of the BelAZ 7513 dump truck deck reinforcement.

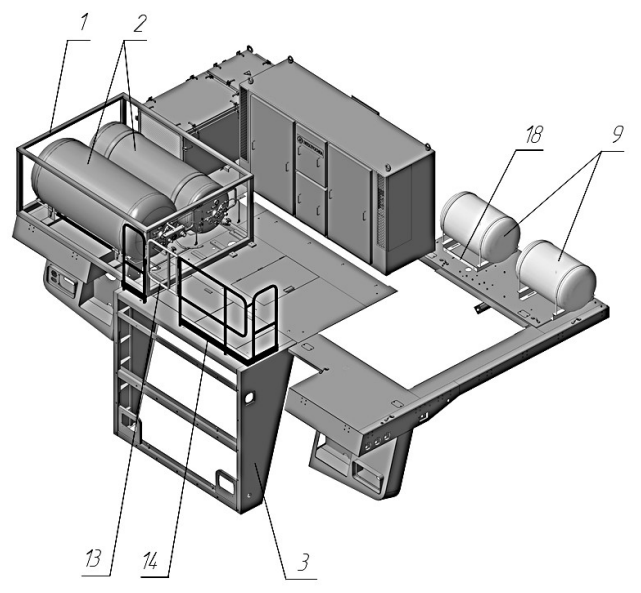

Fig. 3. The option of installing a gate on the front handrail of the deck of the BelAZ 7513 series dump truck.

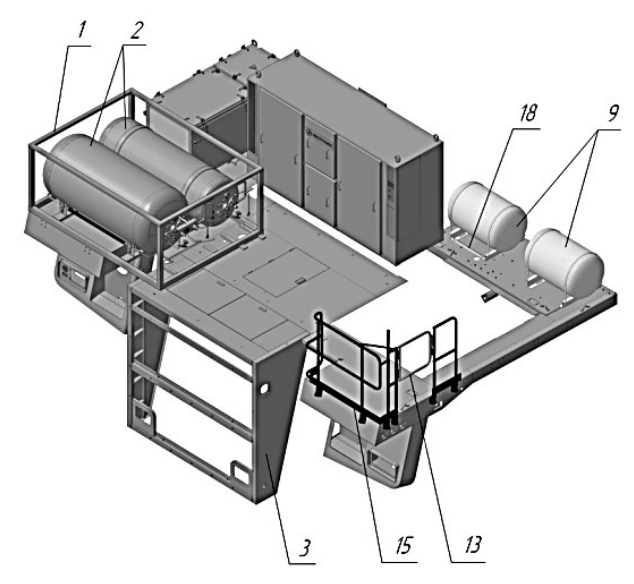

Fig. 4. The option of installing a gate on the left handrail of the deck of the BelAZ 7513 series dump truck. 


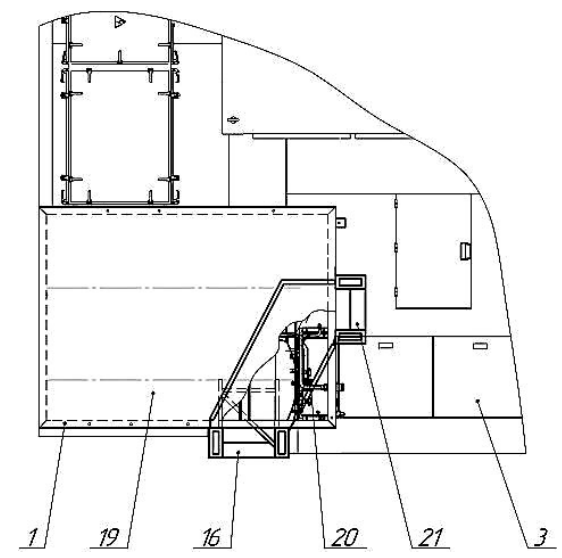

Fig. 5. The diagram of the installation of the modernized ladder on the BelAZ 7513 series dump truck.
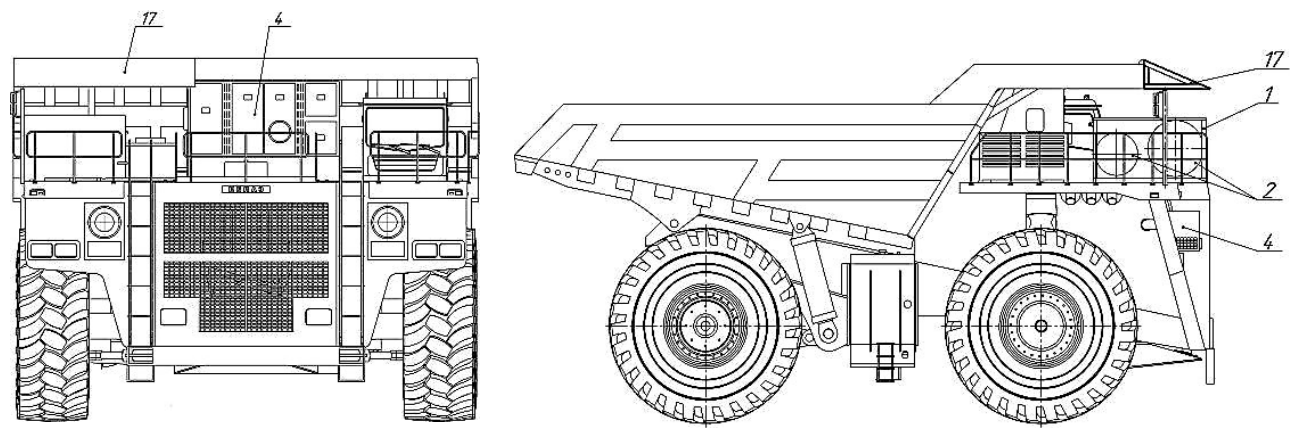

Fig. 6. The diagram for the installation of the protective canopy above the frame with cryogenic fuel tanks fixed in it.

The proposed method consists in the fact that to place the frame 1 (Fig. 1) with cryogenic fuel tanks 2 (hereinafter referred to as the CFT) fixed on it on the deck 3 of the BelAZ 7513 series dump truck (hereinafter referred to as the dump truck) 4 (Fig. 6), the expansion chamber 5 of the cooling system is first transferred towards the cab to a distance that allows placing the frame 1 with the CFT and fix it in this position (Fig. 1). The tool box 6 is transferred to the left corner of the front of the deck 3 in front of the driver's cabin 7 and fixed in this position (for example, by welding) (Fig. 1). Next, the hook (not shown) for transporting the deck 3 located in the place of the initial placement of the tool box 6 is removed, and the battery box 8 is installed in the vacant place (Fig. 1). The air-start system cylinders 9 (Fig. $1,3,4)$ (hereinafter referred to as the cylinders), which were originally located in the front of the deck 3 are mounted at the place from where the battery box 8 was transferred. Each cylinder 9 is fixed to the frame 18 (proportionally divided standard factory frame) (Fig. 3, 4). Each frame 18 with a cylinder 9 mounted on it is fixed on the deck 3, for example, using sets of standard fasteners. In the case of installing the CFT 2 with a total capacity of 1000 liters or more, the deck 3 is reinforced with stiffeners 10 (Fig. 2). Two stiffening ribs 10 are used for this, which are steel pipes that are fastened (for example, welded) on the bottom of the deck 3 at an angle $\alpha=60^{\circ}$ according to the diagram of the dump truck deck reinforcement (Fig. 2). After that, the frame 1 with the CFT 2 is mounted in the front right side of the deck 3 to the place where the cylinders 9 were originally installed, which is fixed to the 
deck 3, for example, using a set of standard fasteners; the length of the fastener is selected so that it passes through the reinforcement of the deck (Fig. 1, 2, 3, 4). The gas discharge pipe 11 from the CFT 2 is installed on the frame 1 with the CFT 2 from the outside of the deck 3; to do this, the silicone outlet branches (not shown in the Figure) mounted on the CFT 2 exhaust valves are connected through a tee into a common branch (not shown in the Figure), which is fixed to the frame 1 with the CFT 2. The metal gas discharge pipe 11 is attached to the outlet end of the branch, which is fixed to the handrails of the deck 3 (Fig. 1). The frame 1 the CFT 2 mounted on the deck 3, due to its overall dimensions, may partially overlap the right rear-view mirror. Therefore, to provide a view from the driver's cabin 7 during operation of the dump truck 4 , the standard rack of the right mirror is replaced by a rack with a length increased by $300-400 \mathrm{~mm}$. The modernized rack with the mirrors 12 is installed in the place provided by the manufacturer and fixed with standard fasteners (Fig. 1). To ensure unhindered access to the frame 1 with the CFT 2 during its refueling with liquefied natural gas, an additional locking door 13 is installed on the front 14 or left 15 handrail or simultaneously on both handrails of the deck 3 (Fig. 3.4), depending on the need. To do this, $500 \mathrm{~mm}$ wide cuts are made in the standard front 14 or left 15 handrails, and the doors 13 are made from the cut out parts and fixed with welded metal hinges (not shown in the Figure) on one of the remaining halves of the handrails 14, 15 and are fixed in the closed position on the other halves of the handrails 14 and 15 with a latch or other locking device (not shown in the Figure). Since the frame 1 with the CFT 2 overlaps the right standard ladder of the dump truck 4 (not shown in the Figure), which makes it difficult to climb to the deck 3 from this side, a modernized ladder 16 is mounted, which is manufactured by changing the design of the standard ladder ( fig. 5). For this, the fastening of the upper part of the ladder is lengthened and fixed (for example, by welding) on the frame of the dump truck 4 at right angles to the horizon plane. The steps of the ladder are deployed so that, when installing the ladder on the dump truck 4 , they are parallel to the horizon plane, and are fixed in this position on the ladder (for example, by welding). For safety, the frame 1 with CFT 2 is covered from above with a metal sheet 19, on top of which the additional handrails 20 and the ladder for lowering to the deck 21 are installed (Fig. 5). A protective canopy 17 (Fig. 6) is installed on the right side of the dump truck body 4, directly above the frame 1 with the CFT 2, for additional protection of the CFT 2 from external influences when loading and hauling, as well as minimizing atmospheric precipitation on the CFT 2. The protective canopy 17 is a frame metal structure made of corners, welded with a slope in one direction, to remove precipitation and other undesirable materials and substances. A metal sheet (position not shown) with a thickness of $10 \mathrm{~mm}$ or more is welded onto the outer surface of the canopy frame. The protective canopy 17 is installed and fixed on the right side of the end face of the dump truck 4 by welding (Fig. 6) [20].

As mentioned above, the cryogenic fuel tank is installed into the frame metal structure, which is mounted on the dump truck deck. This arrangement greatly simplifies the installation of the cryogenic fuel tank and reduces the number of preparatory measures, as well as increases the facilities of access to the cryogenic fuel tank for refueling and maintenance. The ability to directly monitor the cryogenic fuel tank from the driver's seat increases the safety during gas/diesel dual-fuel operation of a mining truck and allows responding quickly in case of emergency. Due to the fact that the cryogenic fuel tank is installed directly on the deck, it becomes possible to increase the capacity of the installed tanks, as well as the installation of several tanks, which allows increasing the performance of the rock mass hauling process by reducing the number of refueling cycles per shift. To control the level of filling and pressure in the cryogenic fuel tanks, a level gauge is installed in the driver's cab displaying information received from capacitive sensors mounted directly in the cryogenic fuel tanks. 
The successful implementation of the proposed method is confirmed by the project for equipping mining trucks with cryogenic onboard fuel systems, implemented in practice by Sibir-Energo (Novokuznetsk, Russia). In the process of implementing the project, according to the proposed method, the frame with the cryogenic fuel tank with volumes of 850 and 500 liters placed on it was installed on the deck of the BelAZ 75131 mining dump truck (Fig. 7).
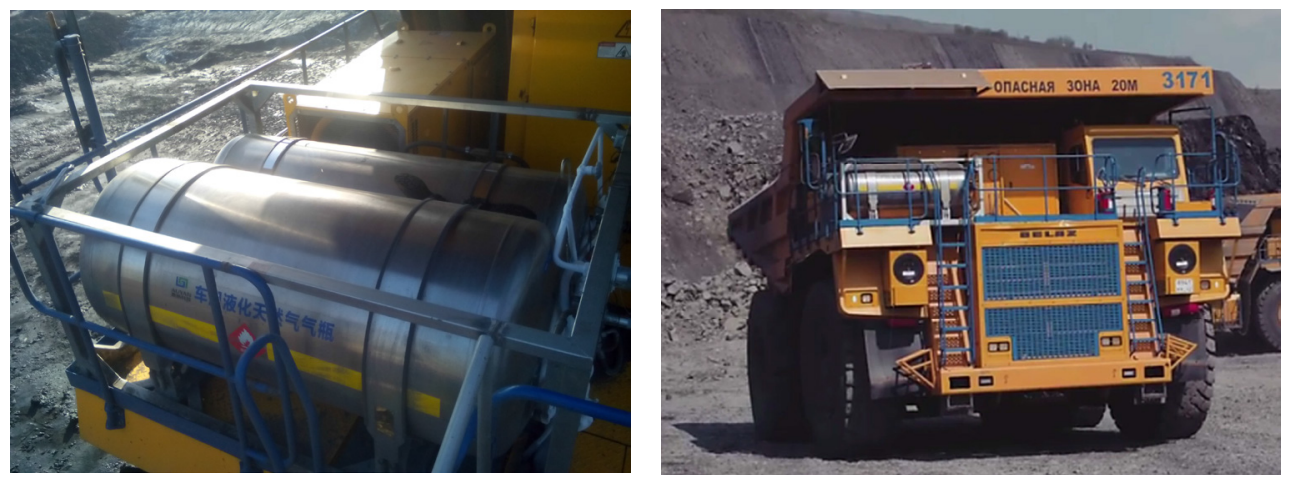

Fig. 7. Two horizontal cryogenic fuel tanks with volumes of 850 and 500 liters installed on the deck of the BelAZ 75131 dump truck.

\section{Conclusion}

The proposed method for installing cryogenic fuel tanks allows:

- simplifying the installation of cryogenic fuel tanks on the deck of the BelAZ 7513 mining dump trucks;

- improving safety during operation of the BelAZ 7513 series mining dump truck in its gas/diesel dual-fuel operation using liquefied natural gas - methane;

- increasing the volume of cryogenic fuel tanks installed on the deck of the BelAZ 7513 series mining dump trucks;

- increasing the performance of the rock mass hauling process by reducing the number of fueling cycles per shift of the BelAZ 7513 mining dump trucks;

- simplifying the processes of refueling and maintaining cryogenic fuel tanks installed on the deck of the BelAZ 7513 mining dump trucks.

\section{References}

1. M. L. Khazin, PJPME, 19, 1, 56 (2019)

2. D. M. Dubinkin, Mining Equipment and Electromechanics, 6, 146, (2019)

3. G. M. Dubov, D. S. Trukhmanov, A. A. Chegoshev, V. E. Ashikhmin, E3S Web Conf., 41, 03008 (2018)

4. D. M. Dubinkin, V. Yu. Sadovets, G. O. Kotiev, A. V. Kartashov, Journal of mining and geotechnical engineering, 4, 7, (2019)

5. W. L. Litzke, J. Wegrzyn, SAE Technical Paper, 01, 2067 (2001)

6. J. Osorio-Tejada, E. Llera, S. Scarpellini, WIT Transactions on The Built Environment, 168, 235 (2015)

7. M. L. Khazin, A. P. Tarasov, PJPME, 17:2, 166 (2018) 
8. I. V. Kuznetsov, I. A. Panachev, G.M. Dubov, S.A. Nohrin, Handbook. An Engineering journal, 4, 19 (2019)

9. G. M. Dubov, D. S. Trukhmanov, I. V. Kuznetsov, S. A. Nokhrin, A. N. Sergel, E3S Web Conf., 105, 03018 (2019)

10. G. M. Dubov, D. S. Trukhmanov, S. A. Nokhrin, IOP Conf. Series: Earth and Environ. Sci., 459, 042059 (2020)

11. J.L. Osorio-Tejada, E. Llera-Sastresa, S. Scarpellini, RENEW SUST ENERG REV, 71, 785 (2017)

12. V. Y. Koptev, A. V. Kopteva, IOP Conf. Ser.: Earth Environ. Sci., 87:2, 022010 (2017)

13. K. Cheenkachorn, C. Poompipatpong, C.G. Ho, Energy, 53, 52 (2013)

14. H. A. A. Wahhab, M. A. Ismael, A. Aziz, M.R. Heikal, AJAS, 10:2, 88 (2017)

15. Y. Xing, H. Song, M. Yu et al. Atmosphere, 7:9, 121 (2016)

16. J. Li, B. Wu, G. Mao, Journal of Natural Gas Science and Engineering, 27, 945 (2015).

17. G. M. Dubov, D. S. Trukhmanov, I. V. Kuznetsov, S. A. Nokhrin, A.N. Sergel, E3S Web Conf., 105, 03019 (2019)

18. S. S. Azikhanov, A. R. Bogomolov, G. M. Dubov, S. A. Nokhrin, MATEC Web Conf., 297, 03001 (2019)

19. G. M. Dubov, D. S. Trukhmanov, S. A. Nokhrin, A. N. Sergel, MATEC Web Conf., 297, 03002 (2019)

20. S. A. Nohrin, G. M. Dubov, D. S. Trukhmanov, Patent 2701133 (Rospatent, Moscow, 2019) 